\title{
Los años de California
}

\author{
JOSÉ ENRIQUE RODRÍGUEZ IBÁÑEZ
}

Serían los muy primeros días de enero de 1974. Yo solamente llevaba entonces un trimestre cursando mis estudios de Doctorado en Sociología en la Universidad de California en Santa Bárbara, todavía en período de adaptación y con una considerable querencia hacia los aires de España y lo español. Ello había hecho que, como suele acontecer, no hubiera tardado en integrarme en la colonia de españoles en el campus, la cual actuaba como red de encuentros, información y actividades festivas. Uno de los centros de tal «ted» lo constituía, evidentemente, el Departamento de Español, a algunos de cuyos profesores - Carlos García Barrón, Víctor Fuentes o Enrique Martínez López, por ejemplo- ya había tenido ocasión de conocer, y en el que colaborahan como ayudantes miembros jóvenes de la «colonia». Allí había acudido, por tanto, quién sabe con qué propósito, cuando, de pronto, presencié lo siguiente: un hombre entrado en la sesentena, probablemente con gabardina, gruesas gafas, delgadez tambaleante y gesto de incredulidad, avanzaba a pasos torpes hacia su despacho, proveniente de algún incierto trastero, abrazado a una voluminosa caja de cartón. Este hombre era José Luis Aranguren que se reintegraba -literalmente, con los bultos a cuestas- a su puesto en la Universidad de California, una vez transcurrido el trimestre de otoño, en el que siempre estuvo liberado de docencia, siendo su despacho ocupado por otra persona. Ése fue mi primer encuentro cara a cara con él. En aquel momento no me di a conocer ni entablé conversación alguna. Sin embargo, la imagen me quedó grabada y más de una vcz he reflexionado sobre su posible valor metafórico: el profesor peregrino que combina solidez intelectual y bien ganado prestigio civico con la modesta aceptación de las cargas y estrecheces que la vida pueda deparar.

Al poco me presenté -rompiendo, por cierto, desde un principio, de un modo osado por mi parte, con la barrera del «usted»-, y así comenzó una larga relación de amistad y discipulazgo que nos llevó a María Jesús y a mí a participar de su ámbito familiar y a recibir de él opiniones y confidencias en tono franco y alejado de todo protocolo; relación que sólo su triste fallecimiento ha interrumpido y que desde luego fue y sigue siendo una de mis mayores satisfacciones. En el terreno académico, he de agradecer a Aranguren, y deseo proclamarlo en público, que consintiera en formar parte del comité que juzgó una de las pruebas de mi doctorado norteamericano, y que se prestara a prologar mi primer libro, apoyando su publicación.

Heterodoxo como de costumbre, Aranguren no se tomó su trabajo en California con arreglo a los cánones. No se volvió hacia las áridas especialidades de la filosofía del lenguaje y la teoría de la comunicación, aunque nunca las 
olvidara, ni tampoco dictó cursos de literatura e hispanismo al uso. Más bien se empleó en recrear la historia intelectual y la civilización españolas, cultivando con gusto temas como el moralismo barroco, el 98 y la novelística española posterior a la Guerra Civil. Y, curiosamente, frecuentó con mayor dedicación a los jóvenes y a los veteranos -así, Arturo Serrano Plaja, entonces profesor en Santa Bárbara- que a los hispanistas y estudiosos de edad intermedia.

Por descontado, su cátedra trascendía con mucho las paredes del aula, y era paseando por cualquiera de los rincones del bellísimo campus a orillas del Pacífico, en fiestas a las que siempre era invitado y a las que nunca faltaba, o en un descanso de las interminables sesiones de biblioteca, cuando uno podía extraer de Aranguren lo mejor de su conversación. Tocado por lo general, en aquellos tiempos, con finas camisas de punto de cuello vuelto -turtle necks-, botines y largas patillas, su silueta familiar no desmerecía en medio de tan agresiva floración de juventud estudiantil - téngase presente que en Isla Vista, el barrio universitario de Santa Bárbara, el promedio de edad era de dieciocho años.

Igualmente, Aranguren no rehuía la asistencia a cuantos foros interdisciplinares, conferencias y actividades de toda índole despertaran su curiosidad, bien en calidad de invitado, bien en calidad de simple público, mostrándose entusiasta y sin ningún prurito de actitud deferente. De todo este fermento plural sabía él extraer lo que después, con conocimiento de causa, vertía en los libros publicados en la época.

Muchos de estos libros constituyen reelaboraciones de trabajos periodísticos y artículos, al modo ortcguiano. De tales colaboraciones, Aranguren disfrutaba mucho una que enviaba al mítico Triunfo con periodicidad quincenal y que se basaba en la glosa de libros que estuviese entonces leyendo. Permítase que cuente aquí una primera anécdota: Triunfo era uno de mis vasos comunicantes con la España tardofranquista en la que nunca dejábamos de pensar - tẹníamos, por ejemplo, fundada una Asociación de Estudiantes Españoles Demócratas que denunciaba las arbitrariedades del Gobierno Arias y, una vez muerto Fran$c o$, favorecía la ruptura democrática-. Pues bien, hojeando un buen día uno de los números, me encontré con una caricatura de Aranguren en la sección de chistes. La cosa no hubiera pasado de ahí, de no haberse dado el caso de que la caricatura presentaba al profesor disfrazado de Capitán América, un héroe de comic, especie de Supermán de vía estrecha al servicio de una "América» entendida al estilo de la política de la era Foster Dulles. Se lo comenté a Aranguren, quien no apreció nada el dibujo. Pidió explicaciones, le dijeron que no podían retractarse de una obra gráfica indeperidiente y contratada por series, y entonces él suspendió la colaboración. Luego, claro está, le presentaron excusas y la crítica quincenal de libros fue reanudada.

Como vengo diciendo, Aranguren centró en Santa Bárbara su docencia californiana. Antes había pasado un año dando conferencias en las distintas sedes de la Universidad de California - lo que se conoce como Regents Lec- 
turer-y otro en el campus de La Jolla-San Diego - donde mantuvo cierta relación con Herbert Marcuse, cuyo avieso talante germánico le divertía-; pero es en Santa Bárbara donde fue finalmente contratado de forma regular y donde encontró - como yo mismo- la quintaesencia y el gozo del Califomian way of life. He citado ya algunos nombres. Faltaría a mi papel de evocador del período californiano de Aranguren si no citara también a quienes son hoy personalidades de la Universidad o la cultura españolas y que entonces eran -éramos- ilusionadísimos aspirantes a intelectuales y ciudadanos a la altura de los tiempos que se formaban en todos los sentidos en aquel remanso de excelencia académica, libertad y vanguardia cultural. Quisiera recordar, por orden alfabético, a Paloma Abarca, Emilio Lamo de Espinosa, Enrique Laraña, Magdalena Mora, Leopoldo Pérez Pita, Soledad Puértolas, Rosario Romero Maura, José Miguel Sánchez Molinero y a tantos otros que frecuentaron a Aranguren en Santa Bárbara, considerándole una referencia incxcusablc.

El anecdotario completo daría para muchas más de las páginas que me concede amablemente Isegoría. Me contentaré, por tanto, con rememorar lo que me resulta más notable. Un dato inicial es el hecho de que Aranguren, dada la intermitencia de sus estancias en Santa Bárbara, confiaba siempre a secretarias, amigos o colegas el alquiler de la que sería su casa en invierno y primavera. A veces tenía suerte -así, cuando logró alojarse en la casa de un colega que estaba de permiso sabático-. Pero en otras ocasiones lo que le tocaba despertaba en él las lógicas reacciones. Me acuerdo de un año en cl que cayó en una urbanización para jubilados, con actividades de tercera cdad incluidas. Otra vez le cupo en suerte una casa de sofocante decoración, cuyo dormitorio, según confesaba él mismo, a lo que más se asemejaba era a un boudoir.

En cuanto a acontecimientos concretos, una de las cosas que tantas veces hemos mentado jocosamente al cabo del tiempo es lo que no me resisto ahora a contar. Era un domingo radiante de mayo y habíamos quedado María Jesús, Magdalena Mora y yo en hacer una excursión con él a La Purísima, una de las más bellas misiones franciscanas de California (después de la de Santa Bárbara, naturalmente, que por algo es conocida como The Queen of Missions). La Purísima es hoy un parque nacional sujeto al férreo horario anglosajón, que clausura la jornada a las cinco de la tarde. Nosotros a esa hora, como todo el mundo hispano comprenderá, ni nos percatábamos del reloj, felices y contentos como estábamos a la vera del riachuelo que discurre por aquellos frondosos parajes. Cuando la conversación ya no daba mucho más de sí y hacíamos planes de cena, iniciamos el camino de retorno al aparcamiento. Alli comprobamos horrorizados que sólo quedaba mi modesto «escarabajo» Volkswagen, junto con un encolerizado ranger que se disponía a denunciarnos. La presencia senior de Aranguren logró que todo quedara en una letanía de reprimendas, sin pasar a mayores, mientras el funcionario nos franqueaba la barrera de salida. A duras penas podiamos contener las carcajadas. 
¿Y qué decir del recital que dio Joan Manuel Serrat en Los Ángeles, y al que toda la colonia, Aranguren en cabeza, acudió? Nada tiene esto de extraordinario en lo tocante a la llegada al teatro y al transcurso del espectáculo. Lo genial llegó a continuación, cuando alguien averiguó el lugar en el que los organizadores iban a ofrecer una fiesta a la que todos nos sentimos invitados. Sin saber muy bien adónde nos dirigíamos, formamos por el intrincado cefalópodo de autopistas que es Los Ángeles una zigzagueante caravana de coches y camionetas que se aproximaban para consultar de ventanilla a ventanilla, con el mejor ritmo cinematográfico de Blake Edwards. Aranguren disfrutaba del torbellino. Menos mal que acabó perdiéndose en el trayecto hacia uno de los múltiples meetings-points que precedieron al definitivo arribo a la fiesta. Porque da la casualidad de que esta fiesta era estrictamente privada y la enloquecida grey santabarbareña no fue muy bien recibida que digamos.

De enero a junio - siempre viajaba a España a tiempo de celebrar su cumpleaños en familia-, José Luis Aranguren vivía en California entre el recuerdo de lo que dejaba atrás durante seis meses y la inmersión en un medio que tanto le inspiraba y rejuvenecía. En 1976 hubiera debido jubilarse, según las leyes entonces en vigor en el Estado californiano (hoy estas leyes han cambiado y no existe la jubilación automática). A requerimiento de sus estudiantes de tercer ciclo, le fue autorizada una prórroga de un curso académico, con objeto de que dichos estudiantes pudieran culminar trabajos y programas bajo su dirección. De este modo consiguió ofrecer una vez más su querido seminario sobre novela española contemporánea. En 1977, aunque nadie lo pudiera imaginar, le llegó la jubilación definitiva. De vuelta entre nosotros - con el recuerdo del flamante Toyota rojo que paseó durante años por Madrid con la exótica matrícula de California - , fue restablecido con todos los honores en su Cátedra complutense, recorrió incansablemente la geografía española, atendiendo cuanta invitación a pronunciar conferencias le era cursada, y ejerció un liderazgo moral único. Así llegó hasta el final. Seguro que en sus pensamientos de despedida algo quedaría de la época californiana, la que le descubrió el secreto de la juventud perpetua y le propició unas peripecias que quienes tuvimos la suerte de compartir con él no olvidaremos jamás. 